\title{
Forensic Science is a Vital Key to Ensuring Proper Assessment and Care for those Suffering from Addictions. Emotional Core Therapy is the Only Behavioral Psychology Approach that is Scientifically Proven to Treat the Root Cause of Addictions Global Efforts are Needed to Bring this Valuable Resource to the World Population
}

\begin{abstract}
Robert A Moylan*
$L C P C, U S A$

*Corresponding author: Robert A Moylan, LCPC, Private Practice, Naperville, Illinois, USA

Submission: 㘹 July 25, 2018; Published: 眥 September 28, 2018

Abstract

More effort is needed to bring proper psychological care to those afflicted with addictive behaviors. Many of the important discoveries in the field of medicine have been brought to light utilizing the efforts of scientists. Now, more than ever, the field of forensic science is needed to ensure proper assessment and treatment for those suffering addictions of all kinds. With new technology from pharmacy labs as well as illicit drug dealers, more powerful potent drugs are hitting the streets of the world. These potent drugs can be highly addictive as well as having lots of side effects. In addition, these drugs, along with alcohol can have painful withdrawal effects. Every effort needs to be made to ensure proper dispensing of all drugs and alcohol occurs. Every effort needs to be made to ensure that the synergistic effects of taking multiple drugs are explained carefully to each patient. These potent drugs can be lethal. More and more people are becoming addicted to drugs and alcohol throughout the world. Clearly an epidemic has occurred. Forensic Science can help aid those suffering by verifying effective behavioral psychology methods and techniques.
\end{abstract}

\section{Introduction}

Currently, there are 677 evidenced based psychology methods approved by SAMSA. SAMSA, which stands for Substance Abuse and Mental Health Services Administration, is the United States oversight organization charged with approving those programs and methods that have met the criteria of having evidence of success. Many programs were grandfathered into getting accepted by SAMSA. The reader is free to examine the SAMSA website to see the increasingly large numbers of programs approved as having some evidence of success. This evidence is only circumstantial, however. There exists no direct scientific proof that any of these 677 programs can successfully treat an addict's stress each time they are used. Indeed, all these programs can readily be disproven to treat addiction stress as none of them treat or discuss the root cause of addiction stress.

Why can none of these programs claim direct scientific proof? The primary reason as that none of these 677 psychological programs treat the root cause of addictions. How can I be sure of this fact? In 2006, I discovered the root cause of addictions and nearly all relationship stress. The behavioral psychology approach that was used to discover the root cause of addiction and psychological stress is called Emotional Core Therapy (ECT) [1]. ECT is an eightstep process that treats the root cause of addiction stress if used properly. What is the root cause of stress? The root cause of stress is the temporary arousal of one of the four true emotions. These emotions are joy, grief, fear, and relief. These emotions are aroused by entering and leaving relationships.

I have a federal copyright on the Emotional Core Therapy behavioral psychology approach which was granted to me by the Register of Copyrights, United States of America. Registration number TX 1-784-168 on November 21 ${ }^{\text {st }}, 2011$ [2]. The Emotional Core Therapy process is the only behavioral psychology process that has never been disproven. Emotional Core Therapy has been tested thousands upon thousands of times. Aspects of each of the eight steps of the Emotional Core Therapy process occur in each stressful 
event an addict encounters in life. This occurs from the time one is born, to the time of death.

For a full explanation of Emotional Core Therapy, along with a detailed link to my manuscript detailing the Emotional Core Therapy process, view the published link below titled, "Using emotional core therapy to effectively treat those suffering debilitating physical injuries requiring rehabilitation". This journal article was published in the "International Physical Medicine and Rehabilitation Journal". This extensive journal article has links to my one-hour training video which is helpful for visual learners to embrace the ECT process. Also included in this journal are extensive explanations of the Emotional Core Therapy process in seven other journals. These journal articles and reviews offer an exhaustive explanation of the ECT process and answer many of the key questions posed by readers and users of ECT over the past 12 years. The Valley International Journal link has the entire Emotional Core Therapy Manuscript along with an abstract which discusses the rules of scientific evidence. Therefore, all forensic scientists and readers of this journal have access to effectively verifying that ECT does treat the root cause of addictions each time it is used properly. This fact is scientifically proven and can be verified by the naked eye for all readers and scientists. In this abstract I explain the necessity for using one's own experience's for obtaining direct scientific proof. The Valley International Journal Article is also attached below. As it the one-hour Emotional Core Therapy Training video.

Over the past 14 years I have been the owner and director of a Substance abuse treatment centre where I utilize the eight step ECT process. My state licensed program has treated over 1,000 substance abusers, including many addicted to drugs or alcohol. Most of my substance abuse clients have been charged with criminal offenses. Many of these are Driving Under the Influence charges. Sometimes criminal defendants have excessive stress from their court requirements which can include community service, fines, incarceration, and mandatory counselling. Being in tune with the criminal defendant's needs is crucial to proper assessment and treatment. My program has been on the National Register of approved substance abuse programs for over a dozen years. The NSSATS website (National Survey of Substance Abuse Treatment Services is overseen by the US Government and SAMSA. I have been listed on their national registry for over ten years. In addition, my program is the only program in the state of Illinois that holds the distinction of being licensed by the Illinois Certification Board (ICB) and NAADAC, the Association for Addiction Professionals, is the premier global membership organization for addiction focused professionals, representing the professional interests of more than 95,000 addiction counselors, educators, and other addiction-focused healthcare professionals in the United States, and the World CEU Alliance as a trainer for addiction professionals. Both the ICB and NAADAC are the largest state and national addiction training and licensing programs in the state and nation. In addition, my course was approved as an online course for several years and has been featured in both schools and hospitals in Illinois. See link below for CEU training.

Once the reader of this Forensic Science and Addiction Re- search has learned the ECT process through the materials in this article, the next step is to apply these techniques to help those afflicted with addictions. The easy application of the eight step ECT process to external variables causing an addict stress, is another reason to embrace ECT as they only readily available behavioral psychology approach currently available worldwide to successfully treat addicts. Why is this so? Let's now look at some of the many issues facing addicts. We have mentioned some of the problems facing addicts in the beginning of this article. These include

1. Managing side effects.

2. Managing the synergistic effects of drugs and alcohol on the body.

3. Managing withdrawal effects.

4. Managing the addictive nature of toxic drugs and being fully informed about the chemical makeup of each drug used. There exist many more stressors facing addicts. Some more of these stressful relationships are

5. examining the specific nature of each drug they are abusing. For example, heroin, cocaine, nicotine, marijuana, alcohol, etc all have varying chemical makeups. The abuser needs time, energy, and support to learn about each stress which is unique to his circumstances.

6. Financial stress related to the purchase of these drugs. Whether they are legal or illegal, these drugs still cost money to use. This can be stressful.

7. Estrangement and stress of family members often can happen to abusers of substances.

8. Legal trouble. Often, abusers of drugs get charged criminally with offenses related to abusing drugs.

\section{Loss of job related to addictions can also happen}

10. Loss of bodily functions and decreased mental and physical functioning. This occurs oftentimes in moderate to severe cases of addictions.

Emotional Core Therapy is well equipped to handle nearly all stress, unique to each patient. Why? The process can be used to identify and release nearly all stress in the environment. Often addictions work can be challenging to assess. For example, let's look at an abuser complaining of stress named John Doe. John drank a six pack of beer, two marijuana cigarettes, and ate an entire pizza. John complains of being hungover and having bodily and mental stress. In addition, John had to work an entire day in the hot sun on his construction site job with heavy manual labour duties. Too entangle and identify each stressor make take much time and energy. But that is essentially the task of an addiction professional. The key in this entire process is to teach the empathy-based process in a supportive and kind manner. Often it takes 20,30 , or more hours to fully learn how to utilize and apply the ECT model. In the Materials and Methods section below we demonstrate how anyone can process the situational stress in their life. This includes all stress, not just addictions. The main stresses one faces in life such as death, 
divorce, financial loss, etc, are discussed.

As the attached journals highlight, a multidisciplinary approach is used with Emotional Core Therapy [3]. The key to ECT is to empower the patient with the knowledge to make informed decisions. This means making use of all fields of medicine, science, psychology, and even religions and prayer, to help those afflicted with drug and alcohol addiction. Some of the journal articles and contributions on Emotional Core Therapy attached come from the fields of Psychiatry, Addiction Medicine, Cognitive Behavioural Sciences, Neurology, Psychology and Family Medicine. Patients suffering addictions are in extensive pain and discomfort. When they tell their doctors and therapists about this pain, it becomes a learning opportunity. Every effort needs to be made to give the patient the most complete and accurate information available at the appropriate time. This includes proper behavioral psychology techniques and methods. There is always a trial and error method when utilizing medication and behavioral psychology. Empathy and support can aid in this transition to optimum self-care by the patient.

\section{Materials and Methods}

Since each person is unique in how they identify and treat relationship stress, the main tools you need to prove effectiveness are your own personal stressful events, my Emotional Core Therapy manuscript and training videos. You will also need the rules of scientific evidence and Emotional Core Therapy link. Access to all these materials can be found in the links below. It may take between 5-50 hours or more to completely master the ECT process. Therefore, time, patience, and a good support system can aid in learning the eight step Emotional Core Therapy process. Remember, the ECT process can be transitioned to use for any relationship stress. The Holmes and Rahe Scale identifies the leading cause of stress for human beings. This scale is attached below [4].

The Valley International Journal link.

http://valleyinternational.net/index.php/ijmsci/article/ view $/ 443$

Emotional Core Therapy Training Video.

https://www.youtube.com/watch?v=ty90E2lqNX8

Access to eight journal links on Emotional Core Therapy with the International Physical Medicine and Rehabilitation Journal.

medcraveonline.com/IPMRJ/IPMRJ-03-00120.pdf
Holmes and Rahe Scale

https://www.stress.org/holmes-rahe-stress-inventory/

Emotional Core Therapy website for CEU Training

www.emotionalcoretherapy.com

\section{Results}

Although many people have utilized parts or all the ECT process successfully to identify and treat stress, these results only provide circumstantial proof of effectiveness. For direct scientific proof, one needs to utilize the eight-step process oneself. See guidelines on scientific evidence below along with the journal review on how to proceed. Scientific evidence can be done with the naked eye. In the case of psychology approaches, this is the most optimum way of demonstrating effectiveness. Since everyone perceives addiction stress differently, results will vary from person to person $[4,5]$.

Emotional Core Therapy Acronyms: My clients write down these acronyms in their book next to the flowchart at the end of each chapter. If you can remember these three acronyms, you are well on your way to identifying and processing the stress you encounter in life through Emotional Core Therapy.

Real Nervous Souls Experience Bodily Stress Racing Everywhere (Acronym for 8 steps)

R: Relationships; N: Needs; S: Five Senses; E: Emotions; B: Bodily; S: Symptoms; R: Releasing Process; E: Equilibrium Balanced

Every Feeling Soul Prospers (Acronym for the four needs that can cause us stress) E: Emotional; F: Financial; S: Spiritual; P: Physical

Just Get for Real (Acronym for the four true emotions) J: Joy; G: Grief; F: Fear; R: Relief.

\section{References}

1. Moylan RA Most effective and most inclusive psychological approach worldwide to treat relationship and psychological stress.

2. (2011) Federal Copyright Number TXu1-784-168 Effective Date of Registration.

3. Holmes TH, Rahe RH (1967) The Social Readjustment Rating Scale. J Psychosom Res 11(2): 213-218.

4. Moylan RA (2017) LCPC Emotional Core Therapy, USA.

5. Moylan RA (2016) Emotional core therapy. IJMSCI 3: 1579-1625
Creative Commons Attribution 4.0 International License

For possible submissions Click Here

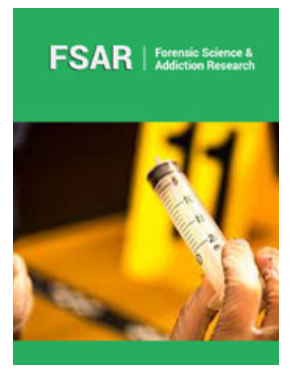

Forensic Science \& Addiction Research

\section{Benefits of Publishing with us}

- High-level peer review and editorial services

- Freely accessible online immediately upon publication

- Authors retain the copyright to their work

- Licensing it under a Creative Commons license

- Visibility through different online platforms 